\title{
Factors associated with patient, and diagnostic delays in Chinese TB patients: a systematic review and meta-analysis
}

Ying $\mathrm{Li}^{1 \dagger}$, John Ehiri ${ }^{2 \dagger}$, Shenglan Tang ${ }^{3}$, Daikun Li ${ }^{4}$, Yongqiao Bian ${ }^{1}$, Hui Lin ${ }^{5}$, Caitlin Marshall ${ }^{2}$ and Jia Cao ${ }^{6,7^{*}}$

\begin{abstract}
Background: Delay in seeking care is a major impediment to effective management of tuberculosis (TB) in China. To elucidate factors that underpin patient and diagnostic delays in TB management, we conducted a systematic review and meta-analysis of factors that are associated with delays in TB care-seeking and diagnosis in the country.

Methods: This review was prepared following standard procedures of the Cochrane Collaboration and the Preferred Reporting Items for Systematic Reviews and Meta-Analyses statement and checklist. Relevant studies published up to November 2012 were identified from three major international and Chinese literature databases: Medline/PubMed, EMBASE and CNKI (China National Knowledge Infrastructure).

Results: We included 29 studies involving 38,947 patients from 17 provinces in China. Qualitative analysis showed that key individual level determinants of delays included socio-demographic and economic factors, mostly poverty, rural residence, lack of health insurance, lower educational attainment, stigma and poor knowledge of TB. Health facility determinants included limited availability of resources to perform prompt diagnosis, lack of qualified health workers and geographical barriers.

Quantitative meta-analysis indicated that living in rural areas was a risk factor for patient delays (pooled odds ratio (OR) (95\% confidence interval (Cl)): $1.79(1.62,1.98))$ and diagnostic delays (pooled OR (95\% Cl): $1.40(1.23,1.59)$ ). Female patients had higher risk of patient delay (pooled OR (95\% Cl): $1.94(1.13,3.33))$. Low educational attainment (primary school and below) was also a risk factor for patient delay (pooled OR $(95 \% \mathrm{Cl}): 2.14(1.03,4.47)$ ). The practice of seeking care first from Traditional Chinese Medicine (TMC) providers was also identified as a risk factor for diagnostic delay (pooled OR (95\% Cl): 5.75 (3.03, 10.94)).
\end{abstract}

Conclusion: Patient and diagnostic delays in TB care are mediated by individual and health facility factors. Population-based interventions that seek to reduce TB stigma and raise awareness about the benefits of early diagnosis and prompt treatment are needed. Policies that remove patients' financial barriers in access to TB care, and integration of the informal care sector into TB control in urban and rural settings are central factors in TB control.

Keywords: Tuberculosis, Patient delay, Diagnosis delay, Risk factors

\footnotetext{
*Correspondence: caojia1962@126.com

${ }^{\dagger}$ Equal contributors

${ }^{6}$ Key Lab of Medical Protection for Electromagnetic Radiation, Ministry of Education of China, College of Preventive Medicine, Third Military Medical University, No. 30 Gaotanyan Road, Shapingba District, Chongqing, China ${ }^{7}$ Toxicology institute, College of Preventive Medicine, Third Military Medical University, No. 30 Gaotanyan Road, Shapingba district, Chongqing 400038, China Full list of author information is available at the end of the article
} 


\section{Background}

Although progress has been made in global tuberculosis (TB) control [1], the disease remains one of the most intractable health challenges in low- and middle-income countries. Globally, TB remains the second leading cause of death from infectious diseases (after HIV/AIDS) [1]. Over the past five years, there has been a marked increase in the number of TB patients diagnosed with multi-drug resistant TB (MDR-TB) [1]. China has the world's second largest tuberculosis epidemic and has contributed significantly to this MDR-TB increase. Results of the 5th National TB Survey in China in 2010 showed an estimated 8.28 million cases of pulmonary TB (РTB) in the country from 2001 to 2010 [2]. In spite of concerted international and national efforts to address TB in the country, annual prevalence (per 100,000 people) declined only minimally from 466 in 2000 to 459 in 2010 [2]. Similarly, incidence of MDR-TB among PTB cases has remained unchanged in the past decade, and resistance to first-line drugs among newly diagnosed TB patients rose from $34.2 \%$ in $2007 / 2008$ [3] to $36.9 \%$ in 2010 [2].

Limited knowledge about signs and symptoms of TB, poor health seeking behavior, and poor diagnosis and disease management in health facilities result in delays in TB diagnosis and treatment, which in turn, increase the risk of $\mathrm{TB}$ transmission and the development of MDR-TB [4]. Available evidence shows that only $47 \%$ of Chinese patients with TB symptoms seek healthcare in a timely fashion and only 59\% comply with prescribed treatment [2].

Early diagnosis and prompt treatment are the core objectives of an effective national TB control program [5]. Persons who experience signs and symptoms of TB should report promptly for diagnosis, and should, if found to have TB, commence treatment immediately [5]. Unfortunately, this process can be disrupted by delay in deciding to visit a TB treatment facility [6-8], delay in obtaining diagnosis [9] and delay in receiving treatment [10]. These types of delays are reported to be common in many low- and middle-income countries which have a high TB burden [8,11-17].

Although reviews conducted on TB care-seeking behavior in sub-Saharan Africa and elsewhere $[18,19]$ suggest that the epidemiology and control of TB are highly associated with socioeconomic and cultural factors, China has a unique social, economic and cultural context. Thus, understanding the sociocultural milieu of delays in TB management in China could help to stem the high burden of TB in the country. A few studies have been conducted to explore factors that influence delays in TB care-seeking, diagnosis and treatment in China. Unfortunately, results of these studies have been largely inconclusive and inconsistent [20-23]. The objective of this review is to critically summarize available literature on factors that underpin delays in pulmonary TB care-seeking, and diagnosis in China. The results could contribute to current efforts to develop a sustainable and effective TB control program in the country.

\section{Methods \\ Definition}

According to the Chinese Ministry of Health (MOHC) [24], "patient delay" is defined as a time interval of more than two weeks between the onset of TB symptoms and the patient's first presentation to a health facility. The Ministry also defines "diagnostic delay" as a time interval of more than two weeks between a patient's first visit to a health facility and the receipt of TB diagnosis.

\section{Search strategy}

The review was prepared following standard procedures of the Cochrane Collaboration [25] and the Preferred Reporting Items for Systematic Reviews and MetaAnalyses (PRISMA) statement and checklist [26] (see Additional file 1). To identify eligible studies on factors associated with TB patient and diagnostic delays published up to November 2012, three major databases, Medline/PubMed, EMBASE and CNKI (China National Knowledge Infrastructure), were searched. We used a mixture of free text and index terms to maximize retrieval of potentially relevant studies. The following terms were used for the PubMed search: "pulmonary tuberculosis and diagnostic delay in China", "pulmonary tuberculosis and health system delay in China", "pulmonary tuberculosis and detection delay in China", "pulmonary tuberculosis and patient delay in China", "pulmonary tuberculosis and health provider delay in China", "pulmonary tuberculosis and doctor delay in China", "pulmonary tuberculosis and identification delay in China". Medline subject search terms included: "tuberculosis, pulmonary"[Mesh]) AND "diagnosis"[Mesh]) AND "China"[Mesh] or "tuberculosis, pulmonary"[Mesh]) AND "patient acceptance of health care"[Mesh]) AND "China"[Mesh]. Searches in Medline/Pubmed were limited to full-text, humans, and English. The search terms used in EMBASE were 'lung tuberculosis'/exp AND 'early diagnosis'/exp AND 'risk factor'/exp, 'lung tuberculosis'/exp AND 'patient'/exp AND 'delayed diagnosis'/exp, 'lung tuberculosis'/exp AND 'delayed diagnosis'/exp AND 'risk factor'/exp, 'lung tuberculosis'/exp AND 'patient'/exp AND 'patient referral'/exp AND 'risk factor'/exp, 'lung tuberculosis'/exp AND 'health care facility'/exp AND 'patient referral'/exp AND 'risk factor'/exp. CNKI is a key national e-publishing project that can be used for searching articles published in 8,200 Chinese journals. It was utilized to search for articles in Chinese. The terms and concepts searched included "patient delay", "diagnostic delay", "risk 
factors for patient delay" and "risk factors for diagnostic delay". We sought unpublished data from the gray literature through Google and Google Scholar searches. We also hand-searched reference lists of identified articles. Two reviewers (JE and YL) conducted the literature searches.

\section{Inclusion/exclusion criteria}

(1) Types of studies: Case-control, cross-sectional and cohort studies were included.

(2) Participants: Patients with pulmonary tuberculosis (including smear positive or negative patients, newly diagnosed cases and those undergoing retreatment).

(3) Exposure variables: We collected data on the following:

(i) Demographic characteristics: marital status (classified as married or living with partner, single, widowed, divorced), age (grouped into 60 years and older, and less than 60 years old), education level (categorized into primary school and below, middle school and above), residence (categorized into rural and urban).

(ii) Risk behavior/lifestyle: smoking and alcohol consumption (categorized into smoker, nonsmoker, alcohol drinker and non-drinker).

(iii) Health systems factors: health facilities (categorized into non-TB health facilities and TB health facilities), health resource related to TB diagnosis, ability of health providers and traffic or geographical barriers.

(4) Outcomes measures: TB patient delay and TB diagnosis delay.

When there was evidence of multiple publications of the same study over time, only the article with a full report was included. Reports on TB suspects, extra-pulmonary TB, HIV infected TB patients, qualitative studies (data collected by qualitative research methods) and studies that focus on PTB patients in Hong Kong, Macao and Taiwan were excluded.

\section{Study selection}

Application of inclusion and exclusion criteria to identified studies was done by two reviewers (DL and YB). Both reviewers independently screened titles and abstracts of identified studies to assess their eligibility for inclusion in the review, using an eligibility form based on the inclusion criteria. Where there were disagreements regarding eligibility of studies, all reviewers participated in the decision about inclusion by discussion and consensus.

\section{Quality assessment}

We assessed the quality of case-control and cohort studies using the Newcastle-Ottawa Scale [27]. For case-control studies, we assessed the adequacy of case and control definition, representativeness of the cases, whether controls were derived from the same population as cases, comparability of cases and controls on the basis of design and analyses, ascertainment of exposure and non-response rates. For cohort studies, we assessed representativeness of the exposed cohort in the study setting, selection of non-exposed cohort, ascertainment of exposure, evidence that participants do not have outcome of interest at recruitment into the study, comparability of cohorts on the basis of design and analyses, outcome assessment and adequacy of follow-up [27]. After assessing the quality of each included study on the basis of these criteria, we assigned a composite quality score ranging from 0 (low) to 8 (high).

For cross-sectional studies, we used the guideline for critical appraisal of cross-sectional studies developed by the National Collaborating Center for Environmental Health [28], which was adapted from a combination of items from the Newcastle-Ottawa Scale [27], the Critical Appraisal Skills Program [29], Critical Appraisals by Elwood [30], and Aschengrau and Seage III [31]. Specifically, we assessed representativeness of the study participants, methods for ascertaining exposure; comparability of exposure groups (including unexposed) in terms of age, sex, socioeconomic status and response bias; determination and validation of outcomes; internal validity; and how confounding factors were assessed and addressed. After reviewing the quality of each included study on the basis of these criteria, we assigned a composite quality score that ranged from 0 (low) to 4 (high). Two reviewers (YL and JE) assessed study quality and reached a consensus grade for each included study.

\section{Data abstraction}

Data from eligible studies were independently abstracted by two reviewers (BY and KL). Differences were resolved by consensus among all reviewers. Data extracted from each study included name of first author, year of publication, type of study design, place of study, type of participants (newly diagnosed/retreatment and smear positive/negative pulmonary TB patients), residence of participants (rural/urban), sampling size, outcome (patient delay/diagnostic delay), information used for comparing analyses (numbers of participants with/without exposure variables) and the main results were extracted for all included studies.

\section{Assessment of heterogeneity}

Heterogeneity was evaluated using the $\mathrm{Q}$ test [32] and the I-squared statistic $\left(\mathrm{I}^{2}=100 \% \times(\mathrm{Q}-\mathrm{df}) / \mathrm{Q}\right)$ [33]. For 
the $\mathrm{Q}$ test, a $P$-value of 0.10 or less was considered statistically significant, indicating marked heterogeneity among studies. Where the $P$-value was $\leq 0.10$, we calculated $\mathrm{I}^{2}$, and studies with heterogeneity levels of $\leq 50 \%$ were deemed acceptable. Where heterogeneity was more than $50 \%$, we conducted subgroup analysis to explore possible reasons for the heterogeneity. For subgroup analyses, the heterogeneity within groups was also tested, using the same statistical methods.

\section{Data synthesis}

The first step of the data analysis involved a qualitative synthesis aimed at summarizing, comparing and contrasting the extracted data. Meta-analyses were then conducted to assess the association among patient delay, diagnostic delay, and gender, age, education, residence, healthcare seeking behaviors (TB health facility for first consultation or seeking care from Traditional Chinese Medicine (TMC) providers) and lifestyle factors (smoking and alcohol use). Only studies that adopted the definitions of patient and diagnostic delays proposed by the Office of TB Control in the MOHC [24] were included in the quantitative meta-analysis. We calculated pooled odds ratio (OR) separately for each factor, using RevMan 5.2 [25]. As noted earlier, we used the fixed effect model where the level of heterogeneity was acceptable (that is, $P=>0.10$, or $P=\leq 0.10$, but $\mathrm{I}^{2}=\leq 50 \%$ ), and the random effects model was used where there was significant heterogeneity (that is, $P=\leq 0.10$, but $\mathrm{I}^{2}=>50 \%$ ). We assessed sources of heterogeneity by conducting sub-group analyses.

\section{Results}

\section{Description of studies}

Figure 1 presents an illustration of the search output. Altogether, the initial search yielded 434 potentially relevant articles. Only 29 studies [14,20-23,34-57] met the criteria for inclusion in the review which involved 38,947 pulmonary TB patients from 17 provinces (Table 1). The

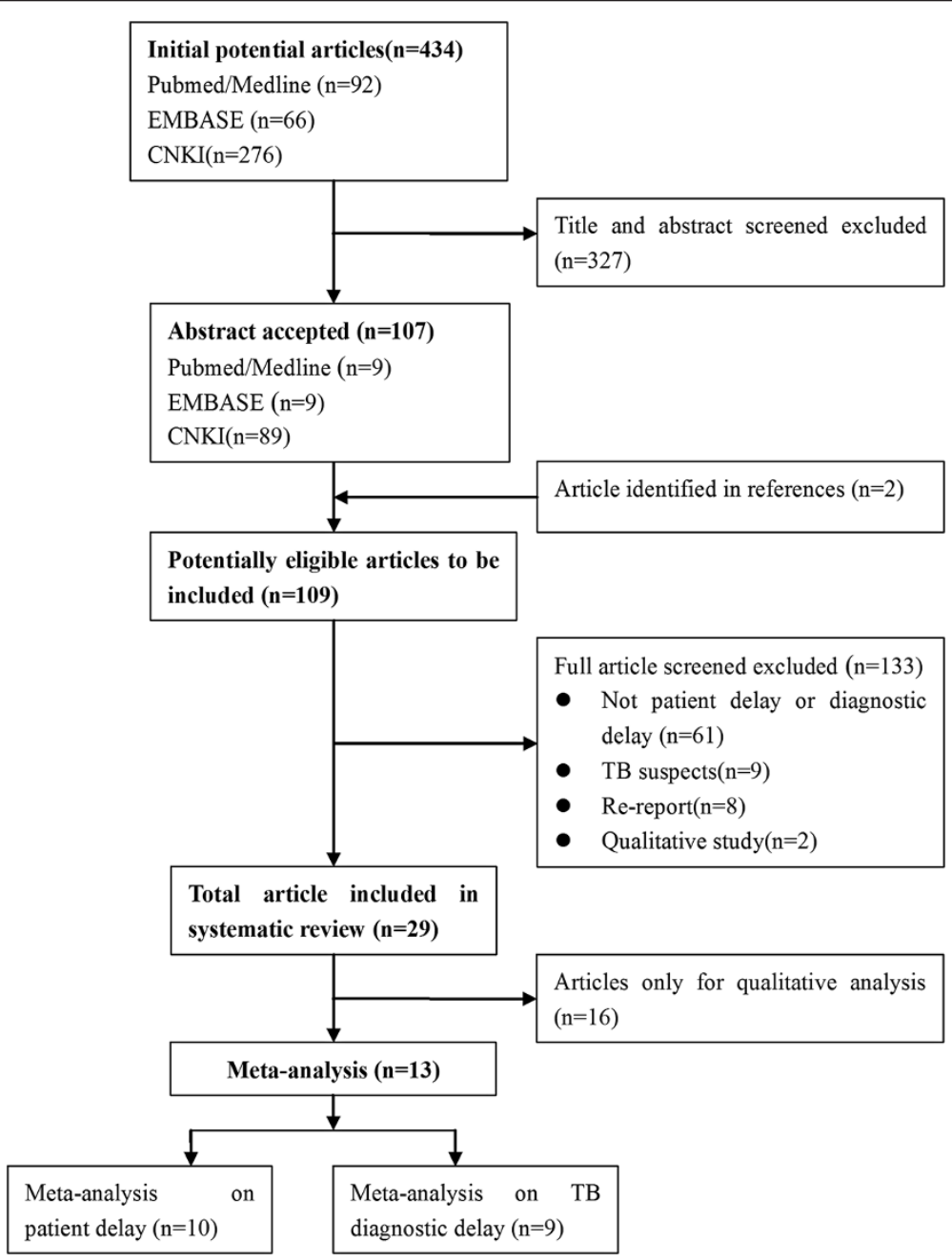

Figure 1 Results of literature search. This figure is a description of the full search process. 
included studies comprised 27 cross-sectional studies, 1 cohort, and 1 case-control study. A majority of the studies (16 out of 29) included newly diagnosed smear-positive PTB patients. The studies applied different definitions of patient and diagnostic delays (Figure 2). However, a majority (23 of 29 studies) adopted the definitions of MOHC (Figure 2A). All 29 studies were included in qualitative data synthesis. However, only 13 cross-sectional studies $[14,20-23,36,38-42,44]$ with 23,917 TB patients had sufficient data to qualify for inclusion in the meta-analysis.

The quality assessment of studies indicated that eight cross-sectional studies [14,34,35,46,48-51] had a high quality score of 4 (out of 4). Eighteen cross-sectional studies had a score of 3 , mainly because they did not control for confounding factors (Table 2). The cohort study [52] and case-control study [53] had high quality scores of 7 and 8, respectively, (out of 8) (Table 3 ).

\section{Data synthesis}

Summary of qualitative findings

Individual level factors Patient's socio-demographic factors: Although results on the association between gender, age and patient, and diagnostic delays were fairly inconsistent (Table 1), a majority of the studies reported that females were more likely than males to experience patient delay $[20,22,42,44]$ and diagnostic delay $[14,35,50]$. A majority of the studies (18 of 29) demonstrated that several indicators of socioeconomic status (low educational attainment, rural residence, lack of health insurance, low income and inability to afford time off work) were risk factors for patient and diagnostic delays.

Patient's healthcare seeking behaviors: Many studies reported the first visit to non-TB control health facilities, notably, traditional healer providers, was a risk factor for diagnostic delay $[14,35,36,39,41,50,54]$.

Patient's TB knowledge/awareness: Seventeen studies demonstrated that lack of TB knowledge (symptoms of $\mathrm{TB}$, transmission mode of $\mathrm{TB}$ and $\mathrm{TB}$ control facilities) and poor TB awareness were risk factors for patient delay (Table 1). Evidence [40] also showed that TB stigma was associated with patient delay, and diagnostic delay (OR (95\% CI): $14.65(6.217,31.78)$ ) [14]. Only one study [35] analyzed the associations among smoking, alcohol use and patient/diagnostic delays. This study demonstrated no significant associations.

Health systems factors Seventeen studies analyzed the relationship between health facility related factors and patient/diagnostic delays. It was found [40-42] that limitation in availability of resources to perform prompt diagnosis (for example, lack of facilities for X-rays and sputum test at village and township level health facilities) was a risk factor for TB diagnostic delay. Shortage of trained health providers at TB control facilities (for example, county TB dispensary and designated county hospitals for TB care), and geographical barriers were important causes of TB diagnostic delay [57], as well as factors related to the health facility staff (health workers' inadequate TB knowledge [22,38], inability to prescribe smear test for TB suspects $[23,39,55]$, inability to refer TB suspects to county TB dispensaries or designated hospitals for TB care $[21,38,55]$ and misdiagnosis $[45,53,55,57])$.

\section{Summary of findings from meta-analysis Patient's} socio-demographic factors: Results of meta-analysis demonstrated patients living in rural areas (Table 4, Figures 3 and 4) were more likely to have patient delays (pooled OR (95\% CI): $1.79(1.62,1.98))$ and diagnostic delays (pooled OR (95\% CI): 1.40 (1.23, 1.59)). Subgroup analysis by gender (Table 4 and Figure 3 ) showed that females who lived in rural areas were more likely to delay seeking healthcare for TB than their male counterparts (pooled OR (95\% CI): 1.94 (1.13, 3.33)). Available data did not indicate that age was an important factor. Results of meta-analysis (Table 4 and Figure 3) showed that patients aged 60 years and older had no higher risk of patient delay than younger individuals (pooled OR (95\% CI): $1.27(0.81,3.63)$ ). As shown in Table 4 and Figure 3, having low educational attainment (primary school and below) was a risk factor for patient delays (pooled OR (95\% CI): 2.14 (1.03, 4.47)).

Patient's healthcare seeking behaviors: Results of metaanalysis indicated that seeking care first from TMC providers was a risk factor for diagnostic delay (pooled OR (95\% CI): 5.75 (3.03, 10.94)). (Table 4 and Figure 4).

\section{Discussion}

An important epidemiological challenge for TB control in China is inadequate and late case detection [58]. Understanding the factors that underpin delays in accessing TB services as well as delays in receiving prompt diagnosis and treatment is central to effective control [5]. In this review, results of qualitative and quantitative analyses indicate that patient and diagnostic delays in TB diagnosis and care are mediated by a constellation of individual patient factors and health systems factors. As noted by Glanz et al. [59], individual-level factors include demographics, knowledge, attitudes, behaviors, beliefs, perceived barriers, skills, gender, level of education, socioeconomic status and so on. Health systems factors include factors that operate within the health system that promote or hinder patients' access and treatment [59]. These include health system financing, health services delivery, resources and support systems, governance community inputs and human resources [60]. At the individual level, results in the review showed that socio-demographic, mostly economic factors (lack of 
Table 1 Studies included in systematic review and meta-analysis

\begin{tabular}{|c|c|c|c|c|c|c|c|}
\hline Studies & $\begin{array}{l}\text { Type of } \\
\text { study }\end{array}$ & Place of studies & Participants & $\begin{array}{l}\text { Residence } \\
\text { (rural/urban) }\end{array}$ & $\begin{array}{l}\text { Sample } \\
\text { size }\end{array}$ & Outcome & Risk factors \\
\hline \multirow[t]{2}{*}{ Zhang 2006 [14] } & \multirow[t]{2}{*}{ CS } & \multirow[t]{2}{*}{ Hunan Province } & \multirow[t]{2}{*}{ New SP PTB } & \multirow[t]{2}{*}{ Rural } & \multirow[t]{2}{*}{318} & $\mathrm{DD}(>2$ weeks $)$ & $\begin{array}{l}\text { PD: No haemoptysis (OR }(95 \% \mathrm{Cl}): 0.119(0.041,0.344)) \text {, } \\
\text { distance to health facility }(\mathrm{OR}(95 \% \mathrm{Cl}): 24.73(6.872,58 . \\
56)) \text {, seeking care from traditional medicine providers } \\
\text { (OR (95\% Cl): } 14.39(4.379,47.30)) \text {, poverty (OR }(95 \% \mathrm{Cl}) \text { : } \\
23.53(8.389,65.96))\end{array}$ \\
\hline & & & & & & PD (>2 weeks) & 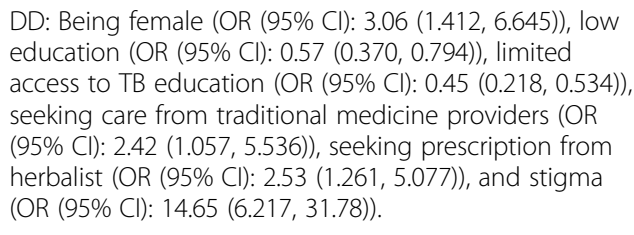 \\
\hline Xi 2011 [20] & CS & $\begin{array}{l}\text { Shandong } \\
\text { Province }\end{array}$ & PTB & Rural & 819 & $\mathrm{DD}(>2$ weeks $)$ & $\begin{array}{l}\text { DD: First consultation with traditional medicine } \\
\text { providers }\end{array}$ \\
\hline He 2009 [21] & CS & Hebei Province & New SP PTB & $\begin{array}{l}\text { migrants from } \\
\text { Rural }\end{array}$ & 168 & PD (>2 weeks) & $\begin{array}{l}\text { PD: Low education level }(P<0.05) \text {, lack of health } \\
\text { insurance }(P<0.01)\end{array}$ \\
\hline \multirow[t]{2}{*}{ Huan 2007 [22] } & \multirow[t]{2}{*}{ CS } & \multirow{2}{*}{$\begin{array}{l}\text { Guizhou } \\
\text { Province }\end{array}$} & \multirow[t]{2}{*}{ New PTB } & \multirow[t]{2}{*}{ Rural/urban } & \multirow[t]{2}{*}{200} & PD (>2 weeks) & PD: Distance to health facility; \\
\hline & & & & & & $\mathrm{DD}$ (>2 weeks) & $\begin{array}{l}\text { DD: Poor equipment in health facility, health worker's } \\
\text { poor TB awareness and knowledge, poor referral }\end{array}$ \\
\hline \multirow[t]{2}{*}{ Wu 2008 [23] } & \multirow[t]{2}{*}{ CS } & \multirow[t]{2}{*}{ Anhui Province } & \multirow[t]{2}{*}{ New SP PTB } & \multirow[t]{2}{*}{ Rural/urban } & \multirow[t]{2}{*}{148} & PD (>2 weeks) & PD: Poor TB awareness \\
\hline & & & & & & $\mathrm{DD}(>2$ weeks $)$ & $\begin{array}{l}\text { DD: Lack of equipment and qualified health workers in } \\
\text { township hospital. }\end{array}$ \\
\hline Wang 2007 [34] & CS & Shanghai & New SP/SN PTB & No description & 222 & $\begin{array}{l}\text { PD was defined as } \\
\text { the duration from the } \\
\text { onset of symptoms to } \\
\text { the first visit to a } \\
\text { doctor in a hospital. }\end{array}$ & $\begin{array}{l}\text { PD: Low income level (OR ( } 95 \% \text { Cl): } 3.859 \text { (1.040, 14.314) } \\
\text { for Level 1/level 4, } 5.369 \text { (1.717, 16.787) for Level 2/level } \\
\text { 4), without Haemoptysis (OR (95\% CI): } 0.347(0.127,0.948))\end{array}$ \\
\hline \multirow[t]{2}{*}{ Bai 2004 [35] } & \multirow[t]{2}{*}{ CS } & \multirow[t]{2}{*}{ Yunnan Province } & \multirow[t]{2}{*}{$\begin{array}{l}\text { New/re-treatment } \\
\text { SP/SN PTB }\end{array}$} & \multirow[t]{2}{*}{ Rural/urban } & \multirow[t]{2}{*}{142} & PD (>2 weeks) & $\begin{array}{l}\text { PD: Being male }(P=0.037) \text {, with spouse }(P=0.010) \text {, no } \\
\text { hemoptysis }(P=0.035) \text {; }\end{array}$ \\
\hline & & & & & & $\mathrm{DD}$ (>2 weeks) & $\begin{array}{l}\text { DD: No night swear }(P=0.030) \text { and chest pain } \\
(P=0.042) \text {, respiratory difficulty }(P=0.029) \text {, no timely } \\
\text { referring }(P=0.001) \text {. }\end{array}$ \\
\hline Liao 2009 [36] & CS & $\begin{array}{l}\text { Zhejiang } \\
\text { Province }\end{array}$ & $\begin{array}{l}\text { New SP PTB, } \\
\text { elderly }\end{array}$ & Rural & 210 & PD (>2 weeks) & $\begin{array}{l}\text { PD: Female }(P=0.018) \text {, lack of TB knowledge } \\
(P=0.003) \text {, Low access to health facility }(P=0.009)\end{array}$ \\
\hline Yang 2010 [37] & CS & $\begin{array}{l}\text { Hujian, Henan, } \\
\text { Liaoling, Xinjiang } \\
\text { Province }\end{array}$ & PTB & Rural & 888 & PD (>2 weeks) & $\begin{array}{l}\text { PD: Being female, the elderly, lack of TB knowledge, } \\
\text { poverty and traffic difficulty }\end{array}$ \\
\hline \multirow[t]{2}{*}{ Zhou 2009 [38] } & \multirow[t]{2}{*}{ CS } & \multirow[t]{2}{*}{ Henan Province } & \multirow[t]{2}{*}{ New PTB } & \multirow[t]{2}{*}{ No description } & \multirow[t]{2}{*}{102} & PD (>2 weeks) & PD: Poor TB awareness; poverty, traffic difficulty; \\
\hline & & & & & & $\mathrm{DD}$ (>2 weeks) & DD: Consulting with traditional medicine providers first \\
\hline
\end{tabular}


Table 1 Studies included in systematic review and meta-analysis (Continued)

\begin{tabular}{|c|c|c|c|c|c|c|c|}
\hline \multirow[t]{2}{*}{ Li 2002 [39] } & \multirow[t]{2}{*}{ CS } & \multirow[t]{2}{*}{ Hunan Province } & \multirow[t]{2}{*}{ New SP PTB } & \multirow[t]{2}{*}{ Rural/urban } & \multirow[t]{2}{*}{3275} & PD (>2 weeks) & $\begin{array}{l}\text { PD: Being male }(P=0.003), 30 \text { to } 44 \text { years old }(P=0 \text {. } \\
\text { 009), poor TB awareness, poverty, traffic difficulty; }\end{array}$ \\
\hline & & & & & & $\mathrm{DD}$ (>2 weeks) & $\begin{array}{l}\text { DD: } 30 \text { to } 44 \text { years old }(P=0.0001) \text {, poor TB } \\
\text { knowledge, without smear test in county hospital }\end{array}$ \\
\hline Shi 2006 [40] & CS & $\begin{array}{l}\text { Liaolin, Hujian, } \\
\text { Xingjiang, Henan } \\
\text { Province }\end{array}$ & New SP PTB & No description & 186 & $\mathrm{DD}(>2$ weeks $)$ & $\begin{array}{l}\text { DD: Consulting traditional medicine providers first, no } \\
\text { resource for TB diagnosis }\end{array}$ \\
\hline \multirow[t]{2}{*}{ Yu 2007 [41] } & \multirow[t]{2}{*}{ CS } & \multirow[t]{2}{*}{ Anhui Province } & \multirow[t]{2}{*}{ New SP PTB } & \multirow[t]{2}{*}{ Rural/urban } & \multirow[t]{2}{*}{17873} & PD (>2 weeks) & PD: Being female ( $P<0.05)$, Rural area; \\
\hline & & & & & & $\mathrm{DD}$ (>2 weeks) & $\begin{array}{l}\text { DD: Rural and diagnosed in non-TB hospital, no } \\
\text { resource for TB diagnosis }\end{array}$ \\
\hline Zhang 2011 [42] & CS & Jiangsu Province & New SP PTB & Rural/urban & 276 & DD (>2 weeks) & $\begin{array}{l}\text { DD: Consulting with traditional medicine providers first, } \\
\text { no resource for TB diagnosis }\end{array}$ \\
\hline Cai 2007 [43] & CS & Gansu Province & $\begin{array}{l}\text { New/retreatment } \\
\text { SP/SN PTB }\end{array}$ & Rural & 150 & PD (>2 weeks) & $\begin{array}{l}\text { PD: The elderly, female, low income, and education } \\
\text { level, poor TB knowledge }\end{array}$ \\
\hline \multirow[t]{2}{*}{ Chai 2008 [44] } & \multirow[t]{2}{*}{ CS } & \multirow[t]{2}{*}{ Henan Province } & \multirow[t]{2}{*}{ New SP PTB } & \multirow[t]{2}{*}{ Rural/urban } & \multirow[t]{2}{*}{200} & PD (>3 weeks) & $\begin{array}{l}\text { PD: Poor TB awareness, no severe symptoms, busy with } \\
\text { work and poverty; stigma for the female }\end{array}$ \\
\hline & & & & & & $\mathrm{DD}(>2$ weeks $)$ & DD: Misdiagnosis, no severe symptoms \\
\hline \multirow[t]{2}{*}{ Tian 2001 [45] } & \multirow[t]{2}{*}{ CS } & \multirow{2}{*}{$\begin{array}{l}\text { Shangdong } \\
\text { Province }\end{array}$} & \multirow[t]{2}{*}{ PTB, the youth } & \multirow[t]{2}{*}{ No description } & \multirow[t]{2}{*}{400} & PD (>2 weeks) & PD: Knowledge of TB control unit and TB awareness \\
\hline & & & & & & $\mathrm{DD}(>2$ weeks $)$ & $\begin{array}{l}\text { DD: No haemoptysis (OR (95\%): } 0.52(0.27,0.98)) \text {, night } \\
\text { swearing (OR (95\%): } 0.44(0.23,0.85)) \text {, chest pain } \\
\text { (OR (95\%): } 2.15(1.12,4.15)) \text {. }\end{array}$ \\
\hline Yang 2011 [46] & CS & Jiangsu Province & New SP PTB & No description & 105 & PD (>2 weeks) & $\begin{array}{l}\text { PD: Poor TB awareness, low income level, distance to } \\
\text { health facilities }\end{array}$ \\
\hline Cao 2002 [47] & CS & $\begin{array}{l}\text { Shangdong } \\
\text { Province }\end{array}$ & PTB, & $\begin{array}{l}\text { migrants from } \\
\text { Rural }\end{array}$ & 314 & PD (>2 weeks) & $\begin{array}{l}\text { PD: Busy at with work (working more than } 6 \text { days per } \\
\text { week) (OR }(95 \%(\mathrm{Cl}): 6.70(2.80,16.03)) \text {, no health } \\
\text { insurance }(\mathrm{OR}(95 \% \mathrm{Cl}): 2.27(1.07,4.82)) \text {, distance to } \\
\text { health facility (OR(95\% CI): } 2.13(0.73,6.18)) \text {, no } \\
\text { hemoptysis (OR(95\% Cl): } 0.30(0.10,0.91)) \text {, }\end{array}$ \\
\hline Geng 2010 [48] & CS & $\begin{array}{l}\text { Shangdong } \\
\text { Province }\end{array}$ & New SP PTB & Rural & 200 & $\begin{array}{l}\text { PD was defined as } \\
\text { the duration from the } \\
\text { onset of cough to the } \\
\text { first visit to any } \\
\text { healthcare provider }\end{array}$ & $\begin{array}{l}\text { PD: Poor TB awareness, low income level, lack of } \\
\text { knowledge of TB control unit }(F=4.39, P<0.01)\end{array}$ \\
\hline \multirow[t]{2}{*}{ Shi 2008 [49] } & \multirow[t]{2}{*}{ CS } & \multirow[t]{2}{*}{$\begin{array}{l}\text { Shangdong } \\
\text { Province }\end{array}$} & \multirow[t]{2}{*}{ New SP TB } & \multirow[t]{2}{*}{ Rural } & \multirow[t]{2}{*}{312} & \multirow{2}{*}{$\begin{array}{l}\text { PD was defined as } \\
\text { the time (in days) } \\
\text { from the onset of } \\
\text { symptoms to first } \\
\text { seeking care at a } \\
\text { health facility }\end{array}$} & $\begin{array}{l}\text { PD: Aged } 40 \text { to } 59 \text { (Adjusted HR ( } 95 \% \text { Cl):0.34 (0.17, } \\
0.699) \text { ), low education (Adjusted HR ( } 95 \% \text { Cl): } 1.91(1.16 \text {, } \\
\text { 3.14)), distance to health facility (Adjusted HR ( } 95 \% \text { Cl): } \\
1.04(0.98,1.11) \text { ) }\end{array}$ \\
\hline & & & & & & & $\begin{array}{l}\text { DD: Being female (Adjusted HR }(95 \% \mathrm{Cl}): 0.63(0.43,0.92)) \text {, } \\
\text { Consulting with traditional medicine providers first } \\
\text { (Adjusted HR }(95 \% \mathrm{Cl}): 1.14(0.52,2.51))\end{array}$ \\
\hline Cheng 2005 [50] & CS & $\begin{array}{l}\text { Shanghai, } \\
\text { Guangdong, } \\
\text { Jiangsu Province }\end{array}$ & New PTB & migrants & 323 & $\mathrm{PD}$ ( $\geq 10$ days) & $\begin{array}{l}\text { PD: Busy with work (AOR }(95 \% \mathrm{Cl}): 1.61(1.03,2.51)) \text {, no } \\
\text { hemoptysis (AOR }(95 \% \mathrm{Cl}): 0.48(0.28,0.85))\end{array}$ \\
\hline
\end{tabular}


Table 1 Studies included in systematic review and meta-analysis (Continued)

\begin{tabular}{|c|c|c|c|c|c|c|c|}
\hline Li 2012 [51] & CS & $\begin{array}{l}\text { Shanghai, } \\
\text { Guangdong and } \\
\text { Jiangsu }\end{array}$ & new PTB & migrant from rural & 323 & $\begin{array}{l}\text { Patient delay } \geq 10 \\
\text { days }\end{array}$ & $\begin{array}{l}\text { Average monthly working days } \geq 24 \text {, and without } \\
\text { hemoptysis or bloody sputum }\end{array}$ \\
\hline Lin 2008 [52] & Cohort & Yunnan Province & $\mathrm{SP} \mathrm{TB}$ & Rural & 10356 & PD ( $\geq 60$ days) & $\begin{array}{l}\text { PD: Geographical barrier, age }>40 \text {, low income level } \\
\text { (Adjusted HR (95\%): } 0.61(0.57,0.65), 0.78(0.67,0.90) \text {, } \\
0.90(0.85,0.94)) \text {. }\end{array}$ \\
\hline \multirow[t]{2}{*}{ Zhang 2008 [53] } & \multirow[t]{2}{*}{ CC } & \multirow[t]{2}{*}{ Jiangsu Province } & \multirow{2}{*}{$\begin{array}{l}\text { Newly SP PTB } \\
\text { elderly }\end{array}$} & \multirow[t]{2}{*}{ No description } & \multirow[t]{2}{*}{102} & PD (>2 weeks) & PD: Poor Tb awareness \\
\hline & & & & & & $\mathrm{DD}$ (>2 weeks) & DD: Misdiagnosis \\
\hline \multirow[t]{2}{*}{ Hou $2001[54]$} & \multirow[t]{2}{*}{ CS } & \multirow[t]{2}{*}{ Hubei Province } & \multirow[t]{2}{*}{ New SP PTB } & \multirow[t]{2}{*}{ No description } & \multirow[t]{2}{*}{823} & PD (>2 weeks) & PD: Poor TB awareness, and low income level \\
\hline & & & & & & $\mathrm{DD}(>2$ weeks $)$ & DD: Consulting with traditional medicine providers first \\
\hline \multirow[t]{2}{*}{ Liu 2000 [55] } & \multirow[t]{2}{*}{ CS } & \multirow[t]{2}{*}{ Hunan Province } & \multirow[t]{2}{*}{ SP PTB, } & \multirow[t]{2}{*}{ Rural/urban } & \multirow[t]{2}{*}{290} & PD (>2 weeks) & PD: Poor TB awareness and knowledge; \\
\hline & & & & & & $\mathrm{DD}(>2$ weeks $)$ & $\begin{array}{l}\text { DD: Misdiagnosis, poor referral, not prescribing smear } \\
\text { test }\end{array}$ \\
\hline Li 2010 [56] & CS & $\begin{array}{l}\text { Shandong } \\
\text { Province }\end{array}$ & PTB, elderly & Rural/urban & 322 & PD (>2 weeks) & PD: 61 to 65 years old and lower income level \\
\hline \multirow[t]{2}{*}{ Lian 2003 [57] } & \multirow[t]{2}{*}{ CS } & \multirow[t]{2}{*}{$\begin{array}{l}\text { Guangzhou } \\
\text { Province }\end{array}$} & \multirow[t]{2}{*}{ Newly SP PTB } & \multirow[t]{2}{*}{ No description } & \multirow[t]{2}{*}{117} & PD (>2 weeks) & $\begin{array}{l}\text { PD: Poor TB awareness, low income level, busy with } \\
\text { work, traffic barrier. }\end{array}$ \\
\hline & & & & & & DD (>2 weeks) & DD: Consulting with traditional medicine providers first \\
\hline
\end{tabular}

Notes:

CS refers to cross-sectional study and CC refers to case-control study. SP refers to smear positive and SN refers to smear negative. PTB refers to pulmonary tuberculosis.

PD refers to patient delay and DD refers to diagnostic delay. $A O R$ adjusted odds ratio, $\mathrm{Cl}$ confidence interval, $H R$ hazard ratio; $O R$ odds ratio. 


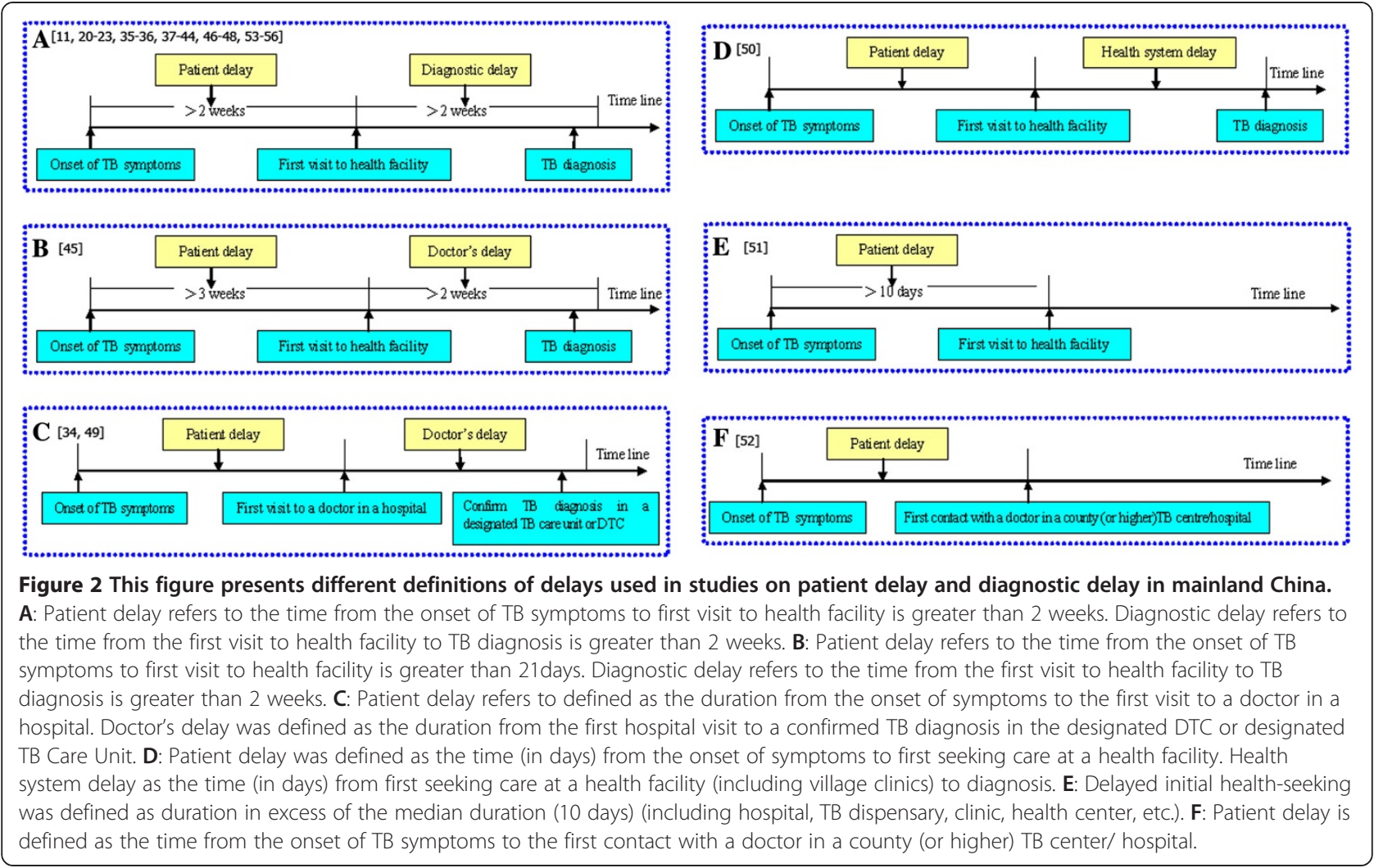

health insurance), rural residence, gender, seeing a TMC provider, educational level and low knowledge of TB are important determinants of patient delay.

The review showed that rural residence was an important determinant of patient delay in seeking and receiving care for $\mathrm{TB}$. It is estimated that a third of $\mathrm{TB}$ suspects in China's rural settings do not seek care after three weeks of persistent cough, and lower-income individuals are less likely to seek care for TB than higherincome individuals [61]. Programs such as DOTS have proven successful in detecting and treating TB infection in China. However, concerns have been raised regarding the impact of such programs on the most vulnerable members of the populations, particularly the rural poor [61]. In spite of the progress made by TB control programs, "the prevalence of active PTB in rural China, particularly the Western region, has in fact, increased" [62]. Thus, greater focus on equitable distribution of TBrelated resources and improved targeting of vulnerable rural populations is of central importance in the control of TB [61].

The review highlighted the practice of seeing a TMC provider as a cultural factor that underpins patient delays in seeking and receiving $\mathrm{TB}$ diagnosis and treatment. Many Chinese TB patients would have visited a TCM provider for their ill-health before seeking care at a formal TB health facility [63]. One potential problem with seeking a traditional provider prior to attending a TB diagnosis and treatment facility is that it results in diagnostic and treatment delays [64]. TCM providers have been shown to recommend Western antibiotics along with traditional healing methods, and generally do not question the effectiveness of Western medicine [63]. Training them to identify early signs and symptoms and prompt referral of suspected cases to TB diagnosis and treatment centers is important. Their propensity to refer cases can be enhanced through an incentive mechanism that rewards them per positive TB case referred to a TB diagnosis and treatment center.

Another cultural aspect of TB diagnosis and treatment delay is the stigma that is attached to the disease, which drives individuals to hide their condition from others, thus hindering them from accessing available diagnosis and treatment services. One study which focused on public awareness about TB concluded that approximately $72 \%$ of respondents held some stigmatizing attitudes towards the disease. Increasing public knowledge and awareness of TB as a disease that can be diagnosed and successfully treated if detected early is important for TB control efforts in the country [65]. Available evidence shows that interventions to reduce the TB stigma can be effective if designed to empower individuals with $\mathrm{TB}$ to resist stigmatizing judgments, while working to change norms about the disease [66]. 
Table 2 Quality assessment of the cross-sectional studies included in systematic review and meta-analysis $\%$

\begin{tabular}{llllllc}
\hline Studies & Type of study & A & B & C & D & Total score \\
\hline Zhang 2006 [14] & CS & 1 & 1 & 1 & 1 & 4 \\
Xi 2011 [20] & CS & 1 & 1 & 0 & 1 & 3 \\
He 2009 [21] & CS & 1 & 1 & 0 & 1 & 3 \\
Huan 2007 [22] & CS & 1 & 1 & 0 & 1 & 3 \\
Wu 2008 [23] & CS & 1 & 1 & 0 & 1 & 3 \\
Wang 2007 [34] & CS & 1 & 1 & 1 & 1 & 4 \\
Bai 2004 [35] & CS & 1 & 1 & 1 & 1 & 4 \\
Liao 2009 [36] & CS & 1 & 1 & 0 & 1 & 3 \\
Yang 2010 [37] & CS & 1 & 1 & 0 & 1 & 3 \\
Zhou 2009 [38] & CS & 1 & 1 & 0 & 1 & 3 \\
Li 2002 [39] & CS & 1 & 1 & 0 & 1 & 3 \\
Shi 2006 [40] & CS & 1 & 1 & 0 & 1 & 3 \\
Yu 2007 [41] & CS & 1 & 1 & 0 & 1 & 3 \\
Zhang 2011 [42] & CS & 1 & 1 & 0 & 1 & 3 \\
Cai 2007 [43] & CS & 1 & 1 & 0 & 1 & 3 \\
Chai 2008 [44] & CS & 1 & 1 & 0 & 1 & 3 \\
Tian 2001 [45] & CS & 1 & 1 & 0 & 1 & 3 \\
Yang 2011 [46] & CS & 1 & 1 & 1 & 1 & 4 \\
Cao 2002 [47] & CS & 1 & 1 & 0 & 1 & 3 \\
Geng 2010 [48] & CS & 1 & 1 & 1 & 1 & 4 \\
Shi 2008 [49] & CS & 1 & 1 & 1 & 1 & 4 \\
Cheng 2005 [50] & CS & 1 & 1 & 1 & 1 & 4 \\
Li 2012 [51] & CS & 1 & 1 & 1 & 1 & 4 \\
Hou 2001 [54] & CS & 1 & 1 & 0 & 1 & 3 \\
Liu 2000 [55] & CS & 1 & 1 & 0 & 1 & 3 \\
Li 2010 [56] & CS & 1 & 1 & 0 & 1 & 3 \\
Lian 2003 [57] & CS & 1 & 0 & 1 & 3 \\
\hline CC refs to Casecont & CS sty; 25 & 3 \\
\hline
\end{tabular}

CC refers to case-control study; CS refers to cross-sectional study. * A. representativeness of study participants, B. proper methods to ascertain exposure, C. comparability of comparing analysis groups and D. lower non-response bias.
Finally, health system financing was been shown to be an important health systems determinant of patient delay in seeking TB care. Although the number of people living below the poverty line in China continues to decline as the economy grows, gross inequity, particularly in the financing of health, remains, as there is still significant difference in terms of socioeconomic development between the Western and Eastern part of China. The innovative, pre-market economy Chinese health system of the 1950s to 1970 s has since disintegrated [67]. In an effort to control the TB epidemic, China has instituted a policy of free diagnosis and anti-TB drug treatment. In spite of this policy, all income groups still have to pay out-of-pocket for the services that are included in a free TB care package, such as a liver protection drug, CT scan exams, and so on, and costs are usually high [68]. This is largely a result of the marketization of healthcare services as a result of economic reform launched in the 1980s in China [69]. Access to medication can be lower and initial access to care may be delayed as a result of financial barriers [70,71].

To counter the impact of financial barriers on TB care, many $\mathrm{TB}$ programs began to incorporate material and financial performance-based incentives for patients, and occasionally, providers in the 1990s. Evaluation studies of these incentive programs show that they can be effective in reducing diagnostic and treatment barriers and delays [72]. Supported with funding from the World Bank, China experimented with an incentive-based approach in the 1990s called the Convergence Management System under the National TB program of the $\mathrm{MOHC}$, whereby the program provided free or subsidized TB diagnosis (including sputum tests and chest $\mathrm{X}$-rays) and treatment (first line anti-TB drugs) to infectious TB patients diagnosed and treated in County TB Dispensaries (CTD) [73]. Under the Convergence Management System a bonus was paid to doctors in general hospitals that referred suspected TB patients to the CTD. Unfortunately, the full potential of this approach could not be reached because the referral bonus was only available to hospital doctors, and not village doctors. A rethink

Table 3 Quality assessment of cohort and case-control studies*

\begin{tabular}{|c|c|c|c|c|c|c|c|c|c|c|c|}
\hline \multirow[t]{2}{*}{ Studies } & \multirow[t]{2}{*}{ Study design } & \multicolumn{4}{|c|}{ A } & \multicolumn{2}{|c|}{ B } & \multicolumn{3}{|c|}{$C$} & \multirow[t]{2}{*}{ Total score } \\
\hline & & $\overline{A 1}$ & A2 & A3 & $\overline{\mathrm{A} 4}$ & $\overline{\mathrm{B} 1}$ & $\overline{B 2}$ & $\overline{C 1}$ & $\mathrm{C2}$ & $\overline{C 3}$ & \\
\hline Lin 2008 [52] & Cohort & 1 & 1 & 1 & 1 & 1 & - & 1 & 1 & 0 & 7 \\
\hline Zhang 2008 [53] & $\mathrm{CC}$ & 1 & 1 & 1 & 1 & 1 & 0 & 1 & 1 & 1 & 8 \\
\hline
\end{tabular}

\section{*Notes:}

For cohort studies: A. selection of the study groups (A1 indicates exposed cohort truly representative, non-exposed cohort drawn from the same community, $\mathrm{A} 3$ right method for ascertainment of exposure, A4 outcome of interest not present at start the representativeness of controls); B. cohorts comparable (B1 control of HIV risk factors except IPV, B2 control of any additional factor); C. outcome measurement (C1 quality of outcome assessment, C2, follow-up long enough for outcomes to occur, C3 complete accounting for cohorts).

For case-control studies: A. selection of the study groups (A1 right case definition, A2 right controls definition, $A 3$ the representativeness of the cases, A4 the representativeness of controls); $B$. comparability of the groups (B1 control of main confounders, B2 control of any additional factor); $C$. ascertainment of the exposure ( 1 appropriate method of exposure ascertainment, $\mathrm{C} 2$ same method of exposure ascertainment for cases and controls, $\mathrm{C} 3$ same non-response rate of case and control groups).

1 indicates the study met the criteria; 0 indicates the study did not meet the criteria; A dash indicates fulfillment of the criteria could not be determined. 
Table 4 Results of meta-analysis of the studies on the factors associated with PTB patient delay

\begin{tabular}{|c|c|c|c|c|c|c|c|}
\hline \multirow[t]{2}{*}{ Factors } & \multirow{2}{*}{$\begin{array}{l}\text { No. of } \\
\text { studies }\end{array}$} & \multirow{2}{*}{$\begin{array}{l}\text { No. of } \\
\text { participants }\end{array}$} & \multicolumn{2}{|c|}{ Variance between studies } & \multirow{2}{*}{$\begin{array}{l}\text { Pooled } \\
\text { OR }\end{array}$} & \multirow[t]{2}{*}{$95 \% \mathrm{Cl}$} & \multirow{2}{*}{$\begin{array}{l}\text { Test for } \\
\text { overall } \\
\text { effect ( } p\end{array}$} \\
\hline & & & $\overline{\mathrm{Q}(p)}$ & $I^{2}(\%)$ & & & \\
\hline \multicolumn{8}{|l|}{ Patient delay } \\
\hline Gender (Female) & 7 & 32,114 & $<0.00001$ & 83 & 1.20 & $(0.90,1.62)$ & 0.22 \\
\hline Gender (Female) in rural & 3 & 1,689 & 0.08 & 60 & 1.94 & $(1.13,3.33)$ & 0.02 \\
\hline Gender (Female) in urban & 4 & 30,425 & 0.0004 & 84 & 0.91 & $(0.65,1.27)$ & 0.59 \\
\hline Severe symptoms & 3 & 940 & 0.78 & 0 & 0.46 & $(0.32,0.68)$ & $<0.0001$ \\
\hline Education & 2 & 575 & 0.49 & 0 & 2.14 & $(1.03,4.47)$ & 0.04 \\
\hline Residence in rural & 2 & 24,363 & 0.91 & 0 & 1.79 & $(1.62,1.98)$ & $<0.0001$ \\
\hline Age ( $\geq 60$ years old) & 3 & 6,941 & 0.009 & 79 & 1.06 & $(0.69,1.63)$ & 0.78 \\
\hline Age ( $\geq 60$ years old) in rural & 2 & 1,388 & 0.41 & 0 & 1.27 & $(0.95,1.70)$ & 0.10 \\
\hline \multicolumn{8}{|l|}{ Diagnostic delay } \\
\hline Gender (Female) & 3 & 21,177 & 0.06 & 64 & 1.00 & $(0.83,1.22)$ & 0.96 \\
\hline Residence in rural & 2 & 15,809 & 0.04 & 76 & 1.40 & $(1.23,1.59)$ & $<0.0001$ \\
\hline $\begin{array}{l}\text { Facility to visit firstly in unorthodox, } \\
\text { non-TB control health facility }\end{array}$ & 3 & 1,317 & 0.16 & 45 & 5.75 & $(3.03,10.94)$ & $<0.0001$ \\
\hline
\end{tabular}

of the contribution of the incentive-based approach to TB management in China is warranted given the enormity of the TB burden in the country.

Similarly, China's once successful Cooperative Medical System (CMS) in the rural areas collapsed in the early 1980s leaving the majority of rural dwellers uninsured. The situation did not improve until 2003 when the
Chinese government started to re-establish New Rural Cooperative Medical Scheme (NRCMS) [64]. The NRCMS covered over $90 \%$ of the rural population in China by 2011. In addition, the government also started to establish Urban Resident Basic Health Insurance (URBMI) covering children and urban residents not covered by Urban Employee Basic Health Insurance [74]. However, both

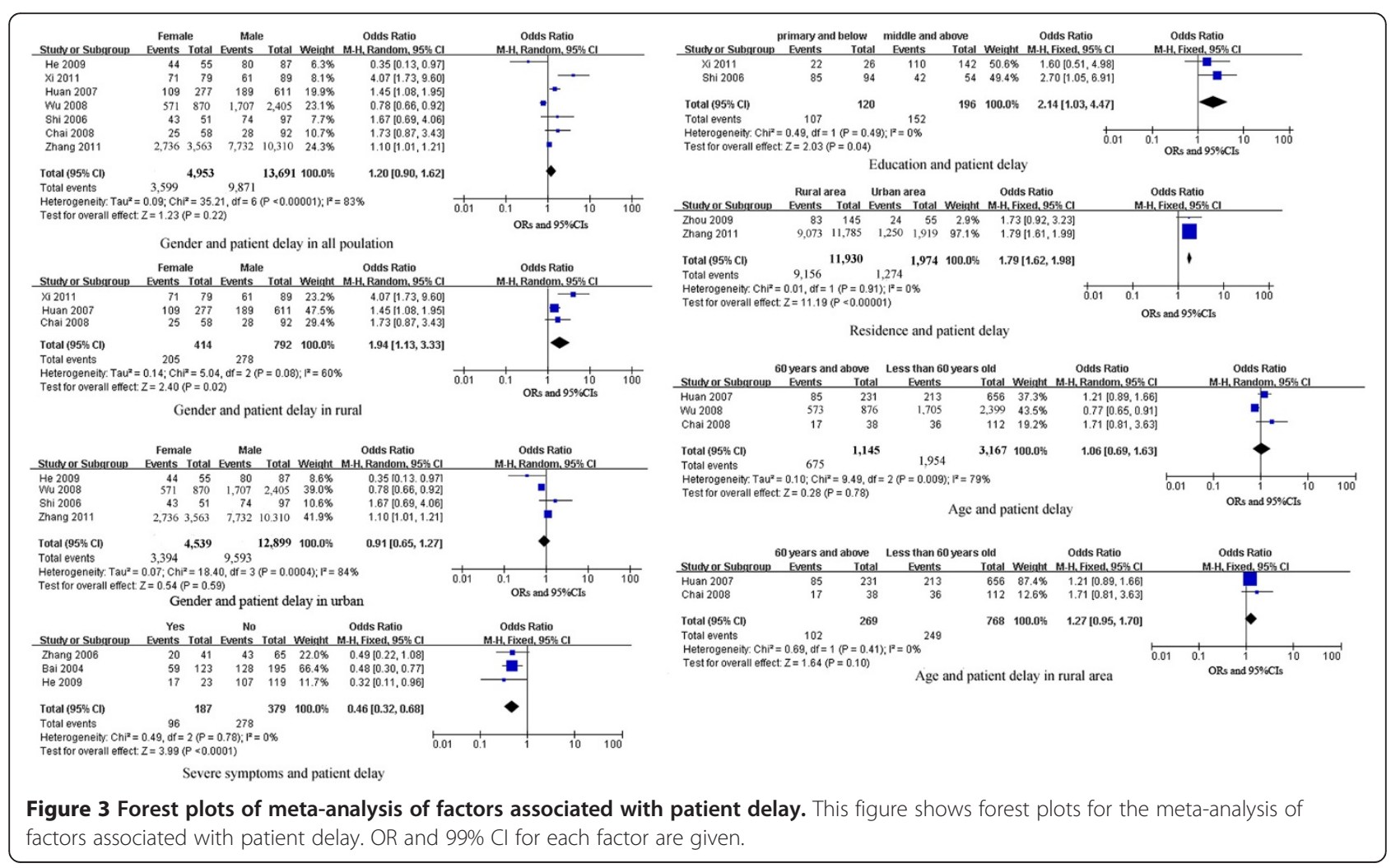




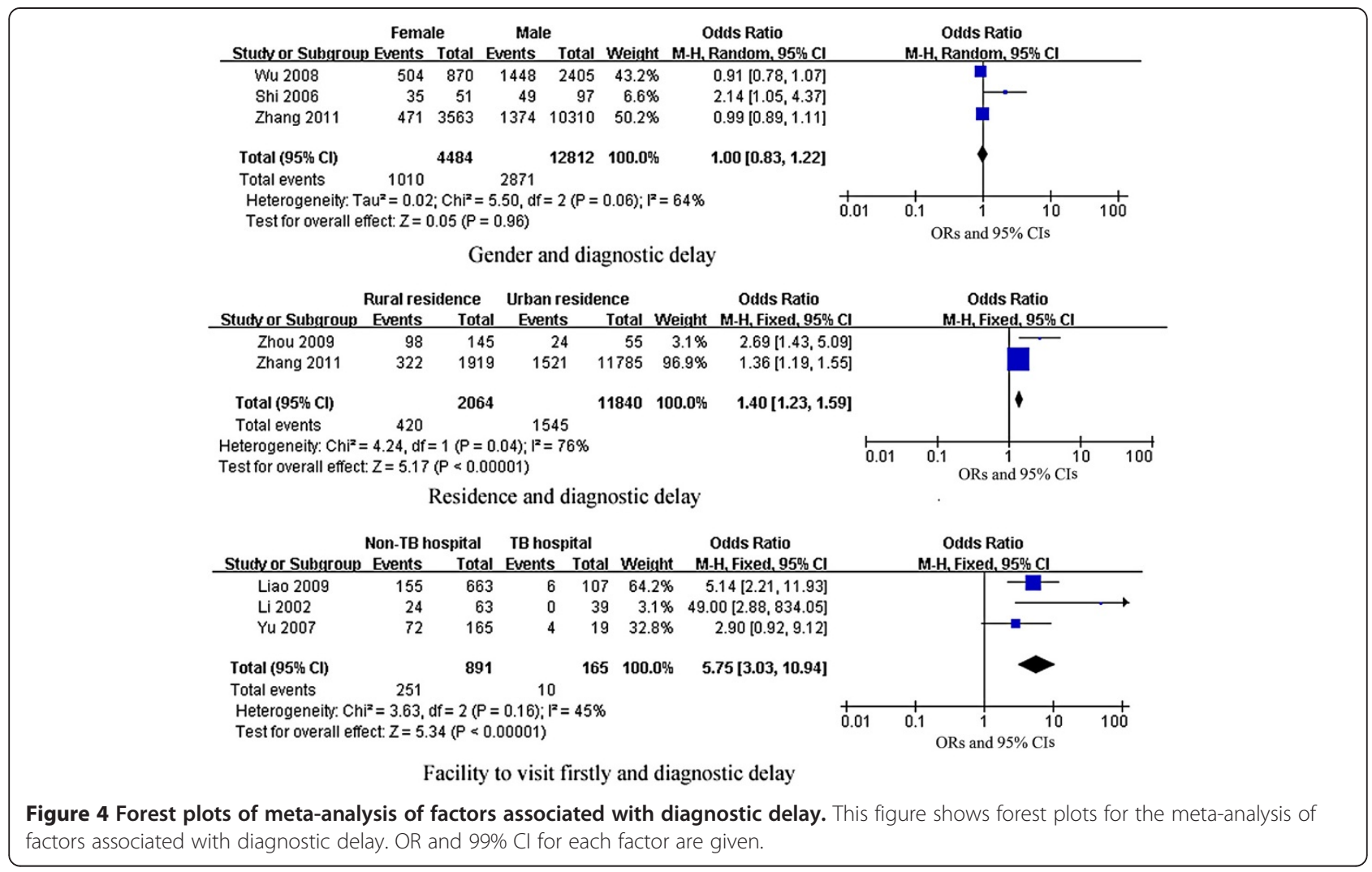

URBMI and NRCMS do not offer a generous service package (for example, only inpatient services are covered in most places of China, and they do not provide a high level of financial protection since both deductible and copayments are high). In spite of this increasing coverage, out-of-pocket medical care costs remain a significant expense, particularly for rural residents. More recently, the free treatment policy has been extended to smear negative patients [75] and the government also provides transportation and nutrition subsidies for low income TB patients [76]. These notwithstanding, patients still make significant amounts of out-of-pocket payments for the total cost of their treatment. Approximately 40\% of healthcare costs are paid out-of-pocket by individuals as a result of deductibles and other expenses. Overall, cost continues to present a major barrier against diagnosis and treatment of TB in the rural communities of China with significant implications for inequity in TB control in the country. Considering the high burden of TB in the country, it is unlikely that the government will be able to provide completely free treatment for all TB cases in the foreseeable future, given the huge financial consequences and the reductions in international donor support for TB control efforts [77].

\section{Limitations}

This review did not identify randomized controlled trials, which was expected since experiments that expose people of diverse backgrounds to TB in order to assess how they seek diagnosis and treatment would be unethical. Consequently, the review included mostly crosssectional, one case-control and one cohort study. These studies have a number of inherent limitations that have the potential to introduce bias in the results of this review. For example, the included cross-sectional studies had low comparability and were fraught with numerous confounders. Although the studies controlled for these confounders using logistic regressions, their residual effect might have introduced some degree of bias to the review.

Most of the available studies had different definitions of patient and diagnostic delays, as well as multiple classification of socio-demographic variables, including age, income, education and type of health facility consulted by TB patients. This limits comparability of the studies, and makes pooled analyses of results difficult. The meta-analysis was restricted to studies that adopted the definition of patient delay proposed by the Office of TB Control in the MOHC (that is, a time interval of more than two weeks between the onset of TB symptoms and the patient's first presentation to a health facility). We acknowledge the limitation in accurately determining actual onset of TB symptoms by patients, given the generally low knowledge of TB among the public [2]. 


\section{Implications for policy and practice}

As findings of this review show, rural residence is an important determinant of delay in seeking diagnosis by TB patients in China. At a time when there is global emphasis on the use of community health workers for health promotion and disease prevention at the community level, the need to resurrect the use of health workers at village and township levels to fight TB in rural China cannot be over-emphasized [67]. They are wellplaced to provide individualized and community-based education and promotion to dispel ignorance and to challenge TB stigma. They can also be effective in referring suspected cases to appropriate sources of diagnosis and treatment, and can serve as key liaisons between communities and the national TB control program.

To address the negative impact of high out-of-pocket payments, it is important to integrate TB control efforts into the overall health system, especially health insurance schemes. The National TB Program (NTP) in China has recently started to work with the Ministry of Civil Affairs that is responsible for medical financing assistance for the poor to ensure that TB patients, particularly MDR-TB patients, can be diagnosed in a timely fashion and treated successfully, regardless of their ability to pay [64]. It is also important for the China CDC to develop measures to ensure that clinical guidelines for TB diagnosis and case management are effectively implemented not only in TB dispensaries and TB-designated hospitals, but also in the general hospitals of China. Training of health workers in effective implementation of established guidelines for TB diagnosis and treatment should also be seen as an important component of the arsenal available for addressing the high burden of TB in China, as is the development of monitoring and evaluation systems to assess the performance of these service providers.

\section{Conclusion}

An important challenge for TB control in China is inadequate and late case detection. Patient and diagnostic delays in TB care are mediated by individual and health facility factors. Population-based interventions that seek to reduce TB stigma and raise awareness about the benefits of early diagnosis and prompt treatment are needed. Policies that remove patients' financial barriers in access to TB care, and integration of the informal care sector into TB control in urban and rural settings are central factors in TB control.

\section{Additional file}

\section{Additional file 1: PRISMA checklist.}

\section{Abbreviations}

Cl: Confidence interval; CMS: Cooperative medical system; CNKI: China national knowledge infrastructure; CTD: County TB dispensaries;
DOTS: Directly observed therapies; MDR-TB: Multi-drug resistant tuberculosis; MOHC: Chinese ministry of health; NRCMS: New rural cooperative medical scheme; OR: Odds ratio; PRISMA: Preferred reporting items for systematic reviews and meta-analyses; PTB: Pulmonary tuberculosis; TB: Tuberculosis; TMC: Traditional Chinese medicine.

\section{Competing interests}

The authors declare that they have no competing interests.

\section{Authors' contributions}

JC designed the review. YL and JE designed the search strategy and searched the literature. YL analyzed data and drafted the manuscript. JE assessed the quality of data analysis and edited the manuscript. DL and YB selected the studies, while $Y L$ and DL extracted data. ST provided technical advice on health system issues related to TB management in China and edited an earlier draft of the manuscript. CM provided resources used in drafting the discussion and edited a later draft of the manuscript. All authors read and approved the final manuscript.

\section{Acknowledgements}

This project was funded by the National Natural Science Foundation of China (Award \# 81001297). The authors would like to thank the library of the Third Military Medical University for the literature search support.

\section{Author details}

${ }^{1}$ Department of Social Medicine and Health Service Management, College of Preventive Medicine, Third Military Medical University, No. 30 Gaotanyan Road, Shapingba District, Chongqing, China. ${ }^{2}$ Division of Health Promotion Sciences, Mel and Enid Zuckerman College of Public Health, University of Arizona, 1295 N. Martin Avenue, Tucson, AZ, USA. ³ Duke Global Health Institute, Duke University, 310 Trent Drive, Durham, NC, USA. ${ }^{4}$ Department of Laboratory Medicine, University-Town Hospital of Chongqing University of Medical Sciences, No. 55 Daxuecheng Road, Shapingba District, Chongqing, China. ${ }^{5}$ Department of Epidemiology, College of Preventive Medicine, Third Military Medical University, No. 30 Gaotanyan Road, Shapingba District, Chongqing, China. ${ }^{6}$ Key Lab of Medical Protection for Electromagnetic Radiation, Ministry of Education of China, College of Preventive Medicine, Third Military Medical University, No. 30 Gaotanyan Road, Shapingba District, Chongqing, China. ${ }^{7}$ Toxicology institute, College of Preventive Medicine, Third Military Medical University, No. 30 Gaotanyan Road, Shapingba district, Chongqing 400038, China.

Received: 15 April 2013 Accepted: 22 May 2013

Published: 2 July 2013

\section{References}

1. World Health Organization: Global tuberculosis report 2012. http://apps who.int/iris/bitstream/10665/75938/1/9789241564502_eng.pdf.

2. Wang Y: [Report of the Fifth National Sampling Survey of TB Epidemiology]. Beijing: Military Medical Science Press; 2011:1-7.

3. Zhao $Y$, Xu S, Wang L, Chin DP, Wang S, Jiang G, Xia H, Zhou Y, Li Q, Ou X, Pang $Y$, Song $Y$, Zhao B, Zhang H, He G, Guo J, Wang Y: National survey of drug-resistant tuberculosis in China. N Engl J Med 2012, 366:2161-2170.

4. Donald PR, van Helden PD: The global burden of tuberculosis-combating drug resistance in difficult times. N Engl J Med 2009, 360:2393-2395.

5. World Health Organization: Early detection of tuberculosis: an overview of approaches, guidelines and tools. WHO Document: WHO/HTM/STB/PSI/ 2011.21. Geneva: World Health Organization; 2011. https://extranet.who.int/ iris/restricted/bitstream/10665/70824/1/WHO_HTM_STB_PSI_2011.21_eng.pdf.

6. Huong NT, Vree M, Duong BD, Khanh VT, Loan VT, Co NV, Borgdorff MW, Cobelens FG: Delays in the diagnosis and treatment of tuberculosis patients in Vietnam: a cross-sectional study. BMC Publ Health 2007, 7:110.

7. Rajeswari R, Chandrasekaran V, Suhadev M, Sivasubramaniam S, Sudha G, Renu G: Factors associated with patient and health system delays in the diagnosis of tuberculosis in South India. Int J Tuberc Lung Dis 2002, 6:789-795.

8. Ngadaya ES, Mfinanga GS, Wandwalo ER, Morkve O: Delay in tuberculosis case detection in Pwani region, Tanzania. A cross sectional study. BMC Health Serv Res 2009, 9:196. 
9. Chang $C T$, Esterman A: Diagnostic delay among pulmonary tuberculosis patients in Sarawak, Malaysia: a cross-sectional study. Rural Remote Health 2007, 7:667

10. Zerbini E, Chirico MC, Salvadores B, Amigot B, Estrada S, Algorry G: Delay in tuberculosis diagnosis and treatment in four provinces of Argentina. Int J Tuberc Lung Dis 2008, 12:63-68.

11. Selvam JM, Wares F, Perumal M, Gopi PG, Sudha G, Chandrasekaran V, Santha T: Health-seeking behavior of new smear-positive TB patients under a DOTS programme in Tamil Nadu, India, 2003. Int J Tuberc Lung Dis 2007, 11:161-167.

12. Zhang QG: Factors associated with delayed identification of PTB. Anthol Med 2006, 25:655-657.

13. Demissie M, Lindtjorn B, Berhane Y: Patient and health service delay in the diagnosis of pulmonary tuberculosis in Ethiopia. BMC Publ Health 2002, 2:23.

14. Ngamvithayapong J, Yanai H, Winkvist A, Diwan V: Health seeking behaviour and diagnosis for pulmonary tuberculosis in an HIV-epidemic mountainous area of Thailand. Int J Tuberc Lung Dis 2001, 5:1013-1020.

15. Sendagire I, Van der Schim LM, Mubiru M, Konde-Lule J, Cobelens F: Long delays and missed opportunities in diagnosing smear-positive pulmonary tuberculosis in Kampala, Uganda: a cross-sectional study. PLoS One 2010, 5:e14459.

16. World Health Organization: Guidelines for the Management of Drug-Resistant Tuberculosis, WHO/TB/96.210 (Rev1). Geneva: WHO; 1997.

17. Golub JE, Mohan Cl, Comstock GW, Chaisson RE: Active case finding of tuberculosis: historical perspective and future prospects. Int J Tuberc Lung Dis 2005, 9:1183-1203.

18. Finnie RK, Khoza LB, van den Borne B, Mabunda T, Abotchie P, Mullen PD: Factors associated with patient and health care system delay in diagnosis and treatment for TB in sub-Saharan African countries with high burdens of TB and HIV. Trop Med Int Health 2011, 16:394-411.

19. Storla DG, Yimer S, Bjune GA: A systematic review of delay in the diagnosis and treatment of tuberculosis. BMC Publ Health 2008, 8:15

20. Xi HF, Li JJ: [Patient delay among migrants PTB]. Mod J Integr Traditional Chinese and Western Med 2011, 20:682-683.

21. He SD, Guo JF: [Factors associated with diagnostic delay of 142 PTB]. China Mod Med 2009, 16:21-22

22. Huan ST, Zhang B, Yan F, Liu XY, Duan MHJ, Zhao FZ, Gong YL: [Analysis on patient delay and reasons for pulmonary tuberculosis in poor rural]. J Chinese Antituberculosis Assoc 2007, 29:70-73.

23. Wu ZJ, Zeng RY, Shen LT, Zhang JF: [Delay in identification of PTB in Shang Yang city]. Pract Prev Med 2008, 15:448-449.

24. TB Control Office in Ministry of Health in China: [Implementation Manual of the World Bank Tuberculosis Control Program in China]. 2nd edition. Beijing, China: Ministry of Health; 1992.

25. Cochrane Collaboration: Review Manager (RevMan) [Computer program]. Version 5.0. Copenhagen: The Nordic Cochrane Centre, the Cochrane Collaboration; 2008.

26. Moher D, Liberati A, Tetzlaff J, Altman D, Group TP: Preferred reporting items for systematic reviews and meta-analyses: The PRISMA statement. Ann Intern Med 2009, 151:264-269.

27. Wells G, Shea B, O'Connell D, Petersen J, Welch V, Tugwell P: The Newcastle-Ottawa Scale (NOS) for assessing the quality of nonrandomized studies in meta-analyses. In Proceedings of the $3 \mathrm{rd}$ Symposium on Systematic Reviews: Beyond the Basics. 3-5 July 2000. Oxford, UK: Center for Statistics in Medicine; 2000

28. National Collaborating Centre for Environment Health: A primer for evaluating the quality of studies on environmental health: critical appraisal of cross-sectional studies. http://www.ncceh.ca/sites/default/files/ Critical_Appraisal_Cross-Sectional_Studies_Aug_2011.pdf.

29. Public Health Resource Unit (PHRU): Critical Appraisal Skills Program (CASP). Oxford, UK: PHRU, Public Health Services; 2006. http://www.civilservice.gov.uk/ wp-content/uploads/2011/09/Qualitative-Appraisal-Tool_tcm6-7385.pdf.

30. Elwood M: Critical Appraisal of Epidemiological Studies and Clinical Trials. 3rd edition. Oxford, UK: Oxford University Press; 2007.

31. Aschengrau A, Seage GR III: Essentials of Epidemiology in Public Health. Sudbury, MA: Jones \& Bartlett Learning; 2003.

32. Cochran BG: The combination of estimates from different experiments. Biometrics 1954, 10:101-129.

33. Higgins JP, Thompson SG: Quantifying heterogeneity in a meta-analysis. Stat Med 2002, 21:1539-1558.
34. Wang W, Sun J, Abdullah AS, Xu B: [Barriers in accessing to tuberculosis care among non-residents in Shanghai: a descriptive study of delays in diagnosis]. European journal of public health. Eur J Public Health 2007; 17:419-423

35. Bai LQ, Xiao SY: [Factors associated with diagnostic delay for patients with smear-positive pulmonary tuberculosis in rural Hunan, China] Chinese Journal of Tuberculosis and Respiratory Diseases 2004; 27:617-620.

36. Liao TH, Xu LZ: [Research on the Affection of Doctors' Disease Diagnose Ability to the Pulmonary Tuberculosis Patient's Economic Burden]. Chinese Health Service Management 2009; 1:8-10

37. Yang JC, Du YP, Zhao YL, Zhang SC: [Patient delay and the impact factors for senile pulmonary tuberculosis in rural area]. Chinese Rural Health Service Administration 2010; 30:300-302.

38. Zhou $Y Z$, Shen $X B$, Shi $X Q$, Lei PY, Li J, Wang SP, et al: [Analysis on causes and countermeasures of delay diagnosis of Pulmonary tuberculosis patients in north GuiZhou]. Modern Preventive Medicine 2009; 36:4462-4464, 4469.

39. Li AX, Wang YL: [Investigation of diagnostic delay of TB in Shang Qiu city]. Henan Journal of Preventive Med 2002; 13:292.

40. Shi SJ, Li L: [Investigation of Correlative Factors leading to Delayed Diagnosis of Smear-positive TB Cases]. Anhui Journal of Prevent Medicine 2006; 12:367-368,391.

41. Yu XH, Wu GY, Gong YL, Zhao FZ, Wang GL: [Spreads the Piece Negative Pulmonary Tuberculosis Sickness Diagnosis Level to the Patient Economic Burden Influence Research]. Chinese Primary Health Care 2007; 21:8-9.

42. Zhang YL, Kan XH, Han L: [Analysis on Delayed-detection Situation of New Smear-positive Cases With Pulmonary Tuberculosis in Anhui Province]. Anhui Journal of Preventive Medicine 2011; 17:328-329,356.

43. Cai T, Wang J, Xu GM: [Survey on the management of newly diagnosed PTB]. Youjiang Medical Journal 2007; 35:703-704.

44. Chai LX, Sun J, Lu XM: [Analysis on the cause of patient delay of PTB in rural area of Dingxi city]. The Journal of the Chinese Antituberculosis Association 2008; 30:553-554

45. Tian HY, Jiao XL, Liu CY: [Survey on the identification delay of newly diagnosed PTB.]. China, Public Health 2001, 17:164

46. Yang ZH, Cui $P$, Chen Z: [Research on detective delay and influence factors in youth patients with pulmonary tuberculosis.]. Clin Focus 2011, 26:1029-1032

47. Cao GH: [Diagnostic delay of newly diagnosed PTB in Zhenzhou City]. Chinese J School Doctor 2002, 12:527.

48. Geng H, Zhou CC, Liu ZM, Xu LZ, Tao WW, Li HT, Bi XL, Wang YF, Zheng YC, Li CJ: [Delay in seeking medical consultation among pulmonary tuberculosis patients in migrants]. Chinese J Public Health 2010, 26:77-978

49. Shi JS, Jia CX, Zhang HM: [The research on detection delay and patient's delay influencing factors of rural new smear positive pulmonary TB of Ji'ning City]. Preven Med Tribune 2008, 14:621-622.

50. Cheng G, Tolhurst R, Li RZ, Meng QY, Tang S: Factors affecting delays in tuberculosis diagnosis in rural China: a case study in four counties in Shandong Province. Trans R Soc Trop Med Hyg 2005, 99:355-362.

51. Li X, Jiang S, Li X, Mei J, Zhong Q, Xu W, Li J, Liu X, Zhang H, Wang L: Predictors on delay of initial health-seeking in new pulmonary tuberculosis cases among migrants population in East China. PLoS One 2012, 7:e31995.

52. Lin X, Chongsuvivatwong V, Geater A, Lijuan R: The effect of geographical distance on TB patient delays in a mountainous province of China. Int J Tuberc Lung Dis 2008, 12:288-293.

53. Zhang $X$, Chen L, Zhang ZJ: Analysis of the cause for misdiagnosis of elderly smear-positive tuberculosis patients. J Clin Pulmonary Med 2008, 13:1449-1450

54. Hou SY, Xiao AQ, Li GM, Liu X: Analysis for diagnostic delay of new smear positive patients. Bull Chinese Antituberculosis Assoc 2001, 23:225-227.

55. Liu HM: Survey on 290 smears positive PTB. J Hengyang Med Coll 2000 28:416-417.

56. Li CJ, Xu LZ, Liao TH, Liu ZM, Cheng J, Wang YF: Diagnosis and treatment of elderly tuberculosis patients in Shandong province. Chinese J Public Health 2010, 26:220-221.

57. Lian GQ, Liu ZM, Huang CM: Diagnostic delay of newly diagnosed PTB. Int Med Health Guidance News 2003, 9:50-51.

58. Zhao P, Li XJ, Zhang SF, Wang XS, Liu CY: Social behavior risk factors for drug resistant tuberculosis in Mainland China: a meta-analysis. J Int Med Res 2012, 40:436-445. 
59. Glanz K, Rimer BK, Viswanath K (Eds): Health Behaviour and Health Education Theory, Research and Practice. 4th edition. San Francisco, USA: John Wiley and Sons; 2008:468-469.

60. Gerein N, Green A, Mirzoev T, Pearson S: Health system impacts on maternal and child health. In Maternal and Child Health: Global Challenges, Programs and Policies. Edited by Ehiri J. New York: Springer; 2009:83-97.

61. Zhang T, Tang S, Jun G, Whitehead M: Persistent problems of access to appropriate, affordable TB services in rural China: experiences of different socio-economic groups. BMC Publ Health 2007, 7:19.

62. Tang S, Tang S: Tuberculosis Control in China: it's Time to Rethink Current Strategies. Durham, NC: Duke Word Press Sites; 2012. https://globalhealth. duke.edu/media/blogs/china/tuberculosis-control-china-its-time-rethinkcurrent-strategies.

63. Center for Disease Control and Prevention: Promoting Cultural Sensitivity: a Practical Guide for Tuberculosis Programs to Persons from China. Atlanta, GA, USA: CDC Press; 2008. http://www.cdc.gov/tb/publications/guidestoolkits/ EthnographicGuides/China/chapters/china.pdf.

64. World Health Organization: Addressing Poverty in TB Control: Options for National TB Control Programmes. WHO/HTM/TB/2005.352; 2005. http:// whalibdoc.who.int/hq/2005/WHO_HTM_TB_2005.352.pdf.

65. Lu SH, Tian BC, Kang XP, Zhang W, Meng XP, Zhang JB, Lo SK: Public awareness of tuberculosis in China: a national survey of 69,253 subjects. Int J Tuberc Lung Dis 2009, 13:1493-1499.

66. Courtwright A, Turner AN: Tuberculosis and stigmatization: pathways and interventions. Public Health Rep 2010, 125:34-42.

67. Hipgrave D: Communicable disease control in China: from Mao to now. $J$ Glob Health 2011, 1:224-238.

68. Liu Q, Smith H, Wang Y, Tang S, Wang Q, Garner P: Tuberculosis patient expenditure on drugs and tests in subsidies, public services in China: a descriptive study. Trop Med Int Health 2010, 15:26-32.

69. Liu Y, Rao K: Providing health insurance in rural China: from research to policy. J Health Polit Policy Law 2006, 31:71-92.

70. Long Q, Smith H, Zhang T, Tang S, Garner P: Patient medical costs for tuberculosis treatment and impact on adherence in China: a systematic review. BMC Publ Health 2011, 11:393.

71. Wei X, Zou G, Yin J, Walley J, Yang HX, Kliner M, et al: Providing financial incentives to rural-to-urban migrants in Shanghai: an intervention study. Infect Dis Poverty 2012, 1:9.

72. Beith A, Eichler R, Weil D: Worldwide: Incentives for Tuberculosis Diagnosis and Treatment. Center for Global Development. http://www. cgdev.org/doc/books/PBI/12_CGD_Eichler_Levine-Ch12.pdf.

73. Cai J, Chen X: Project description. In A Model of Tuberculosis Control in China. Final Evaluation Report on Tuberculosis Control under the World Bank Loaned China Infectious and Endemic Disease Control Project. Edited by Cai J, Chen X. Beijing: People's Medical Publishing House; 2003.

74. Lin W, Liu GG, Chen G: The urban resident basic medical insurance: a landmark reform towards universal coverage in China. Health Econ 2009, 18:S83-S96.

75. Department of Disease Control of Ministry of Health: Guideline on Enforcement of Chinese Tuberculosis Control Program. Beijing, China: Ministry of Health; 2008.

76. Lu H, Yan F, Wang W, Wu L, Ma W, Chen J, Shen X, Mei J: Do transportation subsidies and living allowances improve tuberculosis control outcomes among internal migrants in urban Shanghai, China? West Pac Surveillance Response J 2013, 4:19-24.

77. Jia Z, Cheng S, Wang L: Tuberculosis control in China: striving for sustainability. Lancet 2012, 379:2149.

doi:10.1186/1741-7015-11-156

Cite this article as: Li et al.: Factors associated with patient, and diagnostic delays in Chinese TB patients: a systematic review and metaanalysis. BMC Medicine 2013 11:156.

\section{Submit your next manuscript to BioMed Central and take full advantage of:}

- Convenient online submission

- Thorough peer review

- No space constraints or color figure charges

- Immediate publication on acceptance

- Inclusion in PubMed, CAS, Scopus and Google Scholar

- Research which is freely available for redistribution

Submit your manuscript at www.biomedcentral.com/submit 